\section{The Use of Ultrasonics for Nano-emulsion Preparation}

${ }^{1}$ Particulate Fluids Processing Centre, School of Chemistry/Department of Chemical and Biomolecular Engineering, University of Melbourne, Victoria 3010

${ }^{2}$ Food Science Australia, 671 Sneydes Road, Werribee, VIC 3030, Australia

*Corresponding Author: sandraek@unimelb.edu.au, Tel: +61 38344 6683, Fax: +61 383444153

\title{
Abstract
}

Oil in water emulsions are an important vehicle for the delivery of hydrophobic bioactive compounds into a range of food products. The preparation of very fine emulsions is of increasing interest to the beverage industry, as novel ingredients can be added with negligible impact to solution clarity. In the present study, both a batch and focused flow-through ultrasonic cell were utilized for emulsification with ultrasonic power generation at 20 - $24 \mathrm{kHz}$. Emulsions with a mean droplet size as low as $135 \pm 5 \mathrm{~nm}$ were achieved using a mixture of flaxseed oil and water in the presence of Tween 40 surfactant. Results are comparable to those for emulsions prepared with a microfluidizer operated at $100 \mathrm{MPa}$. The key to efficient ultrasonic emulsification is to determine an optimum ultrasonic energy intensity input for these systems, as excess energy input may lead to an increase in droplet size.

Keywords: Ultrasound, emulsion, triglyceride, surfactant

\section{Industrial Relevance:}

The preparation of oil in water emulsions is a common feature of food processing operations.

The use of ultrasound for this purpose can be competitive or even superior in terms of droplet size and energy efficiency when compared to classical rotor-stator dispersion. It may also be more practicable with respect to production cost, equipment contamination and aseptic processing than a microfluidisation approach. The present paper shows that ultrasound can be 
32 effective in producing nano-emulsions for use in a range of food ingredients. 
Introduction

34 Food grade emulsions formed from oils rich in Omega-3 polyunsaturated fatty acids (PUFA),

35 such as fish oil and flax seed oil are commercially attractive because of the potential health

36 benefits associated with their consumption (Burdge \& Calder 2006; Kolanowski \& Laufenberg

37 2006). Flax seed oil has the extra benefit of a pleasant odor compared to fish oil (Burdge \&

38 Calder 2006). The preparation of such emulsions with small droplet size is of particular interest.

39 Small droplet sizes in general leads to a creamier mouth feel and greater emulsion stability

40 (McClements, 2004). Furthermore, reductions in oil droplet sizes below 100 nanometres have the

41 potential to provide a translucent emulsion (Tadros, Izquierdo, Esquena \& Solans, 2004) that can

42 be incorporated readily into beverages and food gels without loss of opacity. There are a number

43 of mechanisms available for the production of such emulsions. The traditional method employed

44 in the food industry uses valve homogenization (McClements, 2004). This process is energy

45 intensive as only a small percentage of the applied energy is effective (Tadros et al. 2004). Since

46 the mid 1990's a high energy emulsification device, a microfluidizer, has gained prevalence

47 (McClements, 2004; Strawbridge, Ray, Hallett, Tosh \& Dalgleish, 1995). This technique uses

48 particle-particle collision through a microfluidic channel architecture rather than a straight shear

49 field, to cause particle size reduction (McClements, 2004).

51 The use of low frequency ultrasound for emulsion formation is well established, at least on a

52 laboratory scale (Richards, 1929; Abismail, Canselier, Wilhem, Delmas \& Gourdon 1999)

53 However, most work to date has focused on the preparation of synthetic emulsions, for example

54 for the paint industry or in the preparation of polymeric nano-particles. The development of such

55 techniques for the food industry is a much more recent phenomenon (Freitas, Hielscher, Merkle

56 \& Gander, 2006; Jafari, He \& Bandari, 2006). 
58 Ultrasonic emulsification is believed to occur through two mechanisms. Firstly, the application

59 of an acoustic field produces interfacial waves which become unstable, eventually resulting in

60 the eruption of the oil phase into the water medium in the form of droplets (Li \& Fogler 1978a).

61 Secondly, the application of low frequency ultrasound causes acoustic cavitation, that is, the

62 formation and subsequent collapse of microbubbles by the pressure fluctuations of a simple

63 sound wave. Each bubble collapse (an implosion on a microscopic scale) event causes extreme

64 levels of highly localised turbulence. The turbulent micro-implosions act as a very effective

65 method of breaking up primary droplets of dispersed oil into droplets of sub-micron size (Li \&

66 Fogler 1978b).

67

68 Studies to date comparing ultrasonic emulsification with rotor-stator dispersing have found

69 ultrasound to be competitive or even superior in terms of droplet size and energy efficiency (Ma

70 \& Hsu 1999, Abismail et al., 1999, Tadros et al. 2004). Microfluidization has been found to be

71 more efficient than ultrasound, but less practicable with respect to production cost, equipment

72 contamination and aseptic processing (Abismail et al., 1999). Comparing mechanical agitation to

73 ultrasound at low frequency, Tadros et al. (2004) found that for a given desired diameter, the

74 surfactant amount required was reduced, energy consumption (through heat loss) was lower and

75 the ultrasonic emulsions were less polydispersed and more stable. It is the purpose of the present

76 paper to further investigate the usefulness of ultrasound to generate food grade oil-water nano-

77 emulsions and in particular to identify equipment-related constraints. 
Materials and Methods

83 All base emulsions were prepared from unrefined organically grown cold pressed flax seed oil

84 (long chain triglyceride oil) as supplied by Stoney Creek (Victoria, Australia) and reagent grade

85 Tween 40 (C16), as supplied from Sigma Aldrich (Sydney, Australia). Unless otherwise stated,

86 the emulsion formulation was 15 vol\% flaxseed oil, 5.6 vol\% Tween 40 and 79.4 vol\% deionised

87 water.

88

89 Two ultrasonic experimental set-ups were utilised. Batch experiments employed a Branson

90 Sonifier of nominal power $400 \mathrm{~W}$ and frequency $20 \mathrm{kHz}$ with a $19 \mathrm{~mm}$ diameter tip horn. This

91 was placed in a custom-built cylindrical glass cell of internal diameter $60 \mathrm{~mm}$ with in-built

92 cooling jacket. Chilled water at $3.5 \mathrm{C}$ was passed continuously through this jacket. For each

93 experiment, emulsion samples of either 30 , 50 or $75 \mathrm{ml}$ total volume were prepared and pre-

94 mixed at 13,500 rpm with an Ultra-turrax mixer for 2 minutes. The droplet size after pre-mixing

95 was very broad, exhibiting three modes at droplet sizes $0.13,1.0$ and $5.0 \mu \mathrm{m}$, and a volumetric

96 mean size of $0.4 \pm 0.5 \mu \mathrm{m}$. The samples were then placed in the glass cell. The sonifier tip horn

97 was adjusted until it was $2 \mathrm{~cm}$ below the surface of a $75 \mathrm{ml}$ sample or $1 \mathrm{~cm}$ below the surface of a

9830 or $50 \mathrm{ml}$ sample.

99

100 The second series of experiments used a focussed flow through cell powered by a 400S

101 Hielscher Sonifier of 400W nominal power and frequency $24 \mathrm{kHz}$ equipped with a $22 \mathrm{~mm}$

102 sonotrode tip (Figure 1) and flow cell chamber of $5.6 \mathrm{ml}$. In this case, the emulsions were pre-

103 homogenised with a Silverson rotor-stator mixer to a mono-modal droplet size distribution of 104 average $6.4 \pm 0.3 \mu \mathrm{m}$ and then pumped through the cell using a Micropump Model 180 (USA), 
105

106

107

108

109

110

111

112

113

114

115

116

117

118

119

120

121

122

123

124

125 The ultrasonic energy transferred into the emulsion was measured calorimetrically by observing 126 the temperature change of a similar volume of water with time (Kimura et al. 1996; Ratoarinoro,

127 Contamine, Wilhelm, Berlan \& Delmas 1995).

supplied by Process Pumps (Australia). Flowrates through the cell were varied from 20 to $110 \mathrm{~m}$ mL. $\min ^{-1}$, giving residence times of 3 to 19 seconds.

Emulsions were also prepared using a Microfluidics M-110Y microfluidizer (MFIC Corporation, Newton, MA, USA) with a F20 Y $75 \mu$ m interaction chamber and H30 Z $200 \mu \mathrm{m}$ auxiliary chamber inline. Emulsions were prepared by subjecting pre-emulsions to 5 passes (unless otherwise stated) at $100 \mathrm{MPa}$. Pre-emulsions were prepared using a Silverson rotor-stator mixer on its lowest speed setting for 2 minutes and had a average particle size $D_{3,2}$ of $8.37 \pm 0.025 \mu \mathrm{m}$ in a mono-modal distribution. The initial temperature of the pre-emulsion was room temperature, however processing of the emulsions increased the temperature to $50-60^{\circ} \mathrm{C}$.

Emulsion particle size was assessed by laser light scattering using a Mastersizer 2000 (Malvern, Worcestershire, United Kingdom). Samples were diluted to approximately 0.002 wt\%, in an effort to avoid multiple scattering effects. Information about emulsion particle size was then obtained via a best fit between light scattering (Mie) theory and the measured particle size distribution. A refractive index of 1.48 and absorption of 0.02 was used for flax seed oil in Mie theory calculations. Emulsion particle sizes are of the volume - length mean diameter $\mathrm{d}_{4,3}\left(\mathrm{~d}_{4,3}=\right.$ $\left.\sum n_{i} d_{i}^{4} / \Sigma n_{i} d_{i}^{3}\right)$. Emulsion particle size results are an average of three measurements and are quoted as the volume-surface mean diameter $\mathrm{d}_{3,2}\left(\mathrm{~d}_{3,2}=\Sigma n_{i} d_{i}^{3} / \Sigma n_{i} d_{i}^{2}\right)$. Contamine, Wilhelm, Berlan \& Delmas 1995). 


\section{Results and Discussion}

130 The size of an emulsion droplet formed by homogenization is controlled by the interplay

131 between droplet breakup and droplet coalescence (Tadros et al. 2004; McClements, 2004).

132 Droplet break up is controlled by the type and amount of shear applied to droplets as well as the

133 droplets resistance to deformation (Laplace pressure) which is determined by the surfactant

134 (Tadros et al. 2004; McClements, 2004). The rate of droplet coalescence (related to droplet 135 stability) is determined by the ability of the surfactant to rapidly adsorb to the surface of newly

136 formed droplets; this is governed by surfactant surface activity and concentration (Tadros et al.

137 2004; McClements, 2004).

139 In the present study Tween 40 was used as the surfactant and the effect of its concentration can

140 be seen in Figure 2. The relationship between emulsion particle size and Tween content can be

141 explained in terms of surfactant surface coverage. At low Tween contents there is insufficient 142 surfactant, newly formed droplets coalesce and the emulsion droplet size is determined by the 143 surfactant concentration. Initially increasing surfactant concentration results in a large decrease 144 in particle size because more surfactant is able to stabilize the newly formed droplets. Once there 145 is an excess of surfactant, about $2 \%$ Tween, the rate of the decrease in emulsion droplet size with 146 increasing surfactant concentration decreases. This is because the concentration of surfactant in 147 the bulk is sufficient to allow rapid diffusion and adsorption of the surfactant to newly formed 148 droplets. Any further increase in surfactant concentration only leads to a small increase in 149 surfactant diffusion and hence a small decrease in droplet coalescence. In the present system it 150 appears that a Tween content of about 5 to $7 \mathrm{wt} \%$ is close to the limit of the decrease in particle 151 size. Therefore Tween concentrations at this level were used in all subsequent studies. While this 152 may appear to be a relatively large amount of surfactant, the flaxseed emulsions under study in 
153 this paper are likely to be added in only very small quantities to other food substances and hence

154 the total amount of surfactant provided to the consumer will be small.

155

156 Residence Time and Input Power

157 Batch experiments were initially conducted to examine the effect of power intensity, pre-

158 emulsification and sonication time. As shown in Figure 3, a total sonication time of five minutes

159 was found to produce optimum results, with additional sonication providing no greater reduction

160 in droplet size.

161

162 The effect of applied power was next considered. Conventionally it would be expected that the 163 amount of shear would increase with the applied power, the emulsion particle size should then

164 decrease with increasing shear. However the results shown in Figure 4, demonstrate that the

165 droplet size passes through a minimum size at an intermediate power application and then 166 increases at higher power levels. A similar trend between emulsion particle size and applied 167 shear has been observed by others for emulsions made with proteins and/or modified starches 168 (Desrumaux \& Marcand 2002; Jafari et al. 2006; Tornberg 1980). In these studies the effect has 169 been described as "over-processing" which is caused by an increase in emulsion droplet 170 coalescence at the higher shear rates (Desrumaux et al. 2002; Jafari et al. 2006; Tornberg 1980).

171 In the present case, ultrasonic radiation forces (referred to as Bjerknes forces (Leighton 1994)) 172 will increase in intensity as applied power increases. The secondary Bjerknes force will drive 173 emulsion droplets to the nodes and antinodes of the acoustic field. The closer proximity of the 174 droplets at these positions would result in increased droplet coalescence and hence the observed 175 “over-processing” (Pangu \& Feke, 2004). 
177 Alternatively, the conversion of input power to delivered power is less efficient at the higher 178 power levels and this will affect results. Figure 5 shows this relationship between input and

179 delivered power as measured by the temperature increase in the cell over time. The results cover 180 a range of sample volumes with a small sample volume corresponding to a large power density.

181 The results also compare the effect of a pitted horn tip with a polished tip that would again 182 deliver greater power density. It is evident from Figure 5 that as the power density increases; the 183 conversion of this input power into delivered power reduces. This inability for the horn to 184 transfer energy into the solution at high power densities is a well known phenomenon. As the 185 power density increases, the production of acoustic bubbles increases in the area below the horn. 186 Indeed, these bubbles will collect at the nodes of the acoustic field through the same Bjerknes 187 forces as described above. This bubble cloud shields the remainder of the solution from the 188 ultrasonic energy source and hence power transmission decreases.

190 An experiment was also conducted in the batch cell where the pre-emulsification step was 191 omitted. An identical droplet size distribution was obtained, indicating that such pre-mixing is 192 not required to produce a nano-emulsion with ultrasound. However, pre-mixing will always be 193 required in a continuous flow-through arrangement to ensure that a consistent emulsion 194 formulation can be pumped into the cell.

196 In the focused flow through cell, a series of 48 experiments were conducted over a range of 197 nominal input powers (80 to $210 \mathrm{~W}$ ) and pump speeds (20 to $110 \mathrm{~mL} \cdot \mathrm{min}^{-1}$ ). These results were 198 analysed by multiple linear regression. Table 1 summarizes the results of this regression analysis 199 while a selection of this data and the model curve resulting from the regression analysis is 200 presented in Figure 6. This analysis showed similar trends as in the batch cell, that is, a decline in 
201 droplet size as residence time increases (pump speed decreases) and a power input level beyond

202 which droplet coalescence and bubble cloud blanketing of the horn prevents further decreases in

203 droplet size.

204

205 While it was not possible to increase the residence time in the flow through cell by further 206 reducing the pump flow rate, this residence time could be increased by recirculating the emulsion 207 so that it passed through the cell more than once. Gains from multiple passes were incremental, 208 with the surface average mean diameter reducing only from 0.14 to 0.13 micron when the 209 number of passes was increased from one to three at an input power of $340 \mathrm{~W}$ and a pump flow

210 rate of $20 \mathrm{~mL} \cdot \mathrm{min}^{-1}$ (residence time per pass of 17 seconds) (Figure 7). While this represents a $21124 \%$ increase in the number of droplets, it requires a 300\% increase in energy consumption. 212 Further increases in the number of passes had no effect. This suggests that in the flow through 213 arrangement increments in residence time beyond around one minute are ineffective.

215 Also shown in Figure 7 is comparable data obtained using a microfluidisation device. It is clear 216 that the two devices produce similar results. In fact the ultimate difference between ultrasound 217 and microfluidisation is much smaller than other researchers have found using a $24 \mathrm{kHz}$ horn 218 sonicator (Jafari, He \& Bhandari 2006). This is important because a preliminary analysis of the 219 energy requirements suggest that ultrasound may be a more cost effective processing option. It 220 should however be noted that this comparison is valid only for the emulsions considered in this 221 paper. The two devices are likely to produce different results with other formulations, depending 222 on the surface energy and viscosity of the system. 
224 Overall, the minimum droplet size produced in either the batch or flow through sonication cell

225 with the emulsion formulation described was 0.12 micron (obtained in a 50ml sample size batch

226 run at $200 \mathrm{~W}$ nominal power). This droplet size is significantly below that recently reported by

227 Freitas et al. (2006) for comparable food grade emulsions generated by ultrasound (0.4 - 0.6

228 micron). Further, results showed that emulsions produced by either the batch or flow through cell

229 were shelf stable for a period of at least twelve days.

230

231 Equipment Design Issues

232 While batch experiments are useful for laboratory studies, continuous flow equipment will 233 almost always be required in an industrial size application. A major challenge for the 234 introduction of ultrasonic technology is the effective design of such flow through equipment. In 235 particular, it is essential that in such devices, all elements of the fluid experience similar levels of 236 ultrasonic power intensity. With the present flow through cell, it was apparent that a fraction of

237 the fluid flow bypassed the 'hot zone' of the ultrasonic horn tip, as evidenced by a shoulder in 238 the droplet size distribution at higher droplet sizes (see Figure 8). One of the major aims of our 239 ongoing work is to develop better equipment designs that eliminate such effects.

241 A further concern for the commercial application of this technology is that when a standard 242 titanium ultrasonic horn tip is used, titanium ions or particles can be emitted into the product by 243 cavitational abrasion of the sonotrode (Freitas et al. 2006). A further focus of our ongoing work 244 is the development of equipment designs where the ultrasonic transducer is physically separated 245 from the process fluid by an abrasion resistant barrier. This will be essential for food grade 246 applications. 
249 A range of food grade emulsions have been prepared from a flaxseed oil/water mixture. Results 250 show that there is an optimum power input level beyond which droplet coalescence and 251 cavitational bubble cloud formation restricts performance. Increasing residence time reduces 252 droplet sizes to a point, but continued sonication beyond one to five minutes is ineffective. While 253 the batch cell produces better results, continuous equipment is likely to be more viable in a 254 commercial environment. In order to achieve such a commercial outcome, significant additional 255 work is required to optimize equipment design. Bypassing of fluid around the ultrasonic 'hot 256 zone' must be minimized and designs developed where transducer tip erosion does not 257 contaminate process fluids.

\section{Acknowledgements}

260 Funding for this project was partially provided by the University of Melbourne-CSIRO 261 Collaborative Research Support Scheme. Some infrastructure funding was also provided by the 262 Victorian government through a Science Technology and Innovation Infrastructure Grant. This 263 financial assistance is gratefully acknowledged. 


\section{References}

273 Abismail B., Canselier J., Wilhelm A., Delmas H., \& Gourdon C. (1999). Emulsification by ultrasound: drop size distribution and stability. Ultrasonics Sonocheistry, 6, 75-83.

275 Burdge, G.C., \& Calder, P.C. (2006) Dietary alpha-linolenic acid and health-related Outcomes: a metabolic perspective. Nutrition Research Reviews, 19, 26-52.

Desrumaux, A., \& Marcand, J. (2002) Formation of sunflower oil emulsions stabilized by whey proteins with high-pressure homogenization (up to $350 \mathrm{Mpa}$ ): effect of pressure on emulsion characteristics. International Journal of Food Science and Technology, 37, 263-269.

Freitas S., Hielscher G., Merkle H., \& Gander B. (2006). Continuous contact- and contamination-free ultrasonic emulsification-a useful tool for pharmaceutical development and production. Ultrasonics Sonochemistry, 13, 76-85.

Jafari, S. M., He, Y., \& Bhandari, B., (2006) Nano-Emulsion Production by Sonication and Microfluidization-A Comparison, International Journal of Food Properties, 9, 475-485.

Kimura T., Sakamoto T., Leveque J.-M., Sohmiya H., Fujita M., Ikeda S., \& Ando T., (1996). Standardization of ultrasonic power for sonochemical reaction, Ultrasonics Sonochemistry, 3 (3) S157-S161.

Kolanowski, W., \& Laufenberg, G., (2006) Enrichment of food products with polyunsaturated fatty acids by fish oil addition. European Food Research and Technology, 222, 472-477.

291 Leighton T.G., (1994) The Acoustic Bubble Academic Press, London.

292 Li M.K., \& Fogler H.S., (1978a) Acoustic emulsification. Part 1. The instability of the oil-water interface to form the initial droplets Journal of Fluid Mechanics, 88(3), 499-511.

294 Li M.K., \& Fogler H.S., (1978b) Acoustic emulsification. Part 2. Break-up of the larger primary 295 oil droplets in a water medium, Journal of Fluid Mechanics, 88(3), 513-528. 
296 Ma Y.F., Hsu C.C., (1999) Performance of sonication and microfluidization for liquid-liquid 297 emulsification, Pharmaceutical Development And Technology 4 233-240.

298 McClements D.J. (2004) Food Emulsions: Principles, Practices, and Techniques, 2nd edition, 299 CRC Press, Boca Raton, Florida.

300 Pangu, G. D., \& Feke, D. L. (2004) Acoustically aided separation of oil droplets from aqueous 301 emulsions. Chemical Engineering Science 59(15), 3183-3193.

302 Ratoarinoro F., Contamine, Wilhelm A.M., Berlan J., \& Delmas H., (1995) Power measurement 303 in sonochemistry, Ultrasonics Sonochemistry, 2(1), S43-S47.

304 Richards W.T., (1929) The chemical effects of high frequency sound waves I. A study of 305

306 Strawbridge K. B., Ray, E., Hallett F. R., Tosh S. M., \& Dalgleish, D. G., (1995) Measurement 307 emulsifying action Journal of the American Chemical Society, 51, 1724-1729.

Tornberg, E. (1980) Functional characteristics of protein stabilised emulsions: emulsifying behaviour of proteins in a sonifier. Journal of Food Science, 45, 1662-1668. 
Table Caption

318 Table 1 - Summary of statistical parameters arising from a multiple linear regression of the Sauter mean diameter droplet size obtained using the flow through cell.

\section{Figure Captions}

Figure 1 - Diagram of the focussed flow-through ultrasonic cell used for the preparation of nanoemulsions. The cell is equipped with a $22 \mathrm{~mm}$ sonotrode tip and flow cell chamber of $5.6 \mathrm{ml}$ and was powered by a 400S Hielscher Sonifier of 400W nominal power and frequency $24 \mathrm{kHz}$.

Figure 2 - The effect of Tween 40 content on the particle size of 15 vol\% flax seed oil-in-water prepared by microfluidisation (5 passes at $100 \mathrm{MPa}$ ). Error bars are based on two standard deviations, calculated from triplicate measurements on two samples.

Figure 3 - The effect of sonication time for a 50ml sample in the batch cell. Nominal ultrasonic power was $200 \mathrm{~W}$. Error bars are based on two standard deviations, calculated from seven pairs of replicate points.

Figure 4 - The effect of nominal applied power in the batch cell. (a) $50 \mathrm{ml}$ Sample Size (b) $75 \mathrm{ml}$ Sample Size. Error bars are based on two standard deviations, calculated from eight replicate unsonicated samples.

334 Figure 5 - Power calibration results in the batch cell across a range of sample volumes. The $75 \mathrm{ml}$ sample sizes compare a freshly polished horn (unpitted) with a horn tip that has become pitted on the surface and will thus deliver less power. Each power calibration was determined from the measurement of solution temperature at three points in time. The average standard percentage error of the subsequent linear regression of the temperature/time relationship was used to generate the error bars.

Figure 6 - Experimental data obtained with the focused flow through cell at a pump speed of 60 mL. $\mathrm{min}^{-1}$ corresponding to a residence time of 5.6 seconds (symbols). Model curves resulting from multiple linear regression of the full experimental data set (solid lines) are also shown.

Figure 7 - A comparison of ultrasonic emulsification to microfluidisation. Particle size is shown as a function of the number of passes through each device. Ultrasonic results were obtained at $330 \mathrm{~W}$ nominal power and a pump speed of $20 \mathrm{~mL} \cdot \mathrm{min}^{-1}$ (residence time of 17 seconds per pass), with error bars generated from five pairs of replicate points.

Figure 8 - A comparison of results obtained with the batch and flow through cell. Batch results were obtained after 25 minutes sonication at $280 \mathrm{~W}$ nominal input power. Flow through cell results were obtained after a single pass at $350 \mathrm{~W}$ nominal power and a pump speed of 20 $\mathrm{mL} \cdot \mathrm{min}^{-1}$ (residence time of 17 seconds). 
352 Table 1

353

\begin{tabular}{|c|c|c|c|c|c|c|}
\hline $\begin{array}{l}\text { Coefficient of } \\
\text { Variation }\left(R^{2}\right)\end{array}$ & $63 \%$ & & & \multicolumn{2}{|c|}{ F statistic } & 24.7 \\
\hline $\begin{array}{l}\text { Standard } \\
\text { Error }\end{array}$ & 0.032 & & & \multicolumn{2}{|c|}{$\begin{array}{l}\text { Probability of occurring by } \\
\text { chance based on F statistic }\end{array}$} & $1.6 \times 10^{-9}$ \\
\hline \multirow[t]{3}{*}{ Observations } & 48 & & & & & \\
\hline & $\begin{array}{l}\text { Regression } \\
\text { Coefficients }\end{array}$ & $\begin{array}{l}\text { Standard } \\
\text { Error }\end{array}$ & $\begin{array}{c}t \\
\text { Statistic }\end{array}$ & $\begin{array}{l}\text { Probability } \\
\text { Value }\end{array}$ & \multicolumn{2}{|c|}{$\begin{array}{l}\text { 95\% Confidence Interval } \\
\text { based on t-statistic }\end{array}$} \\
\hline & & & & & Lower & Upper \\
\hline Intercept & 0.51 & 0.072 & 7.0 & $1.2 \times 10^{-8}$ & 0.36 & 0.65 \\
\hline $\begin{array}{l}\text { Pump Speed } \\
\left(\mathrm{mL}^{\mathrm{min}}{ }^{-1}\right)\end{array}$ & 0.0014 & 0.00027 & 5.1 & $5.9 \times 10^{-06}$ & 0.00084 & 0.0019 \\
\hline Power(W) & -0.0044 & 0.00099 & -4.4 & $5.9 \times 10^{-05}$ & -0.0064 & -0.0024 \\
\hline $\operatorname{Power}^{2}\left(W^{2}\right)$ & $1.2 \times 10^{-05}$ & $3.4 \times 10^{-06}$ & 3.7 & 0.00061 & $5.64 \times 10^{-06}$ & $1.92 \times 10^{-05}$ \\
\hline
\end{tabular}

354

355 
Figure 1

357

358

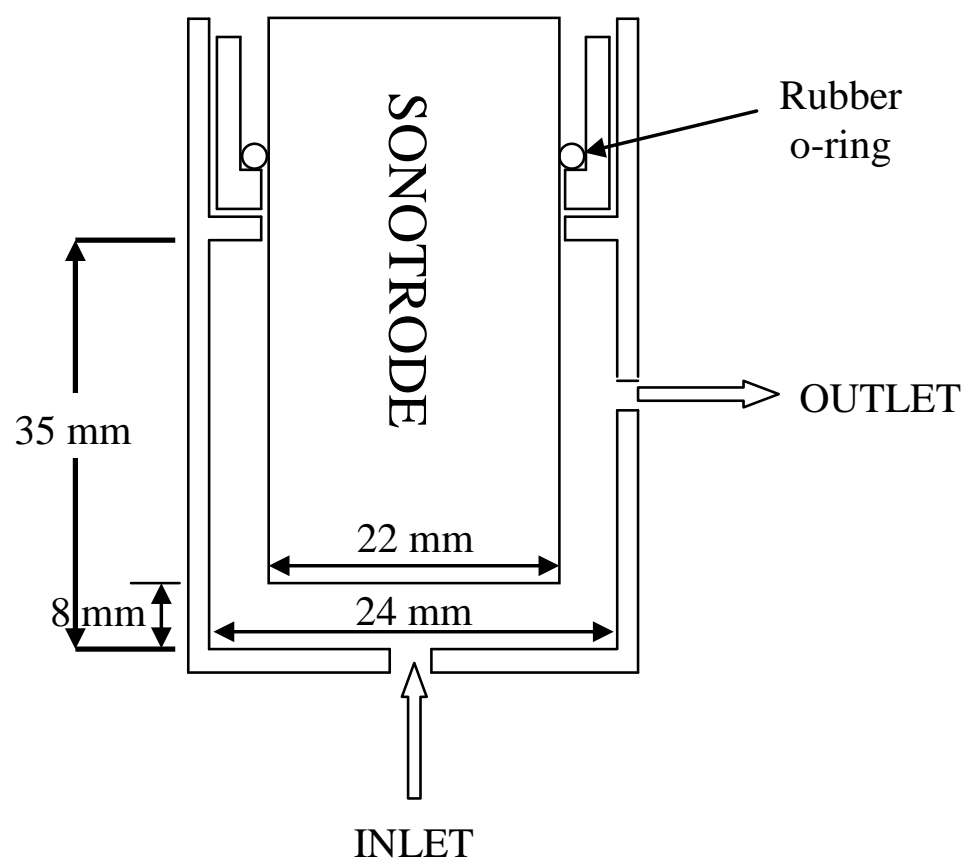


$359 \quad$ Figure 2

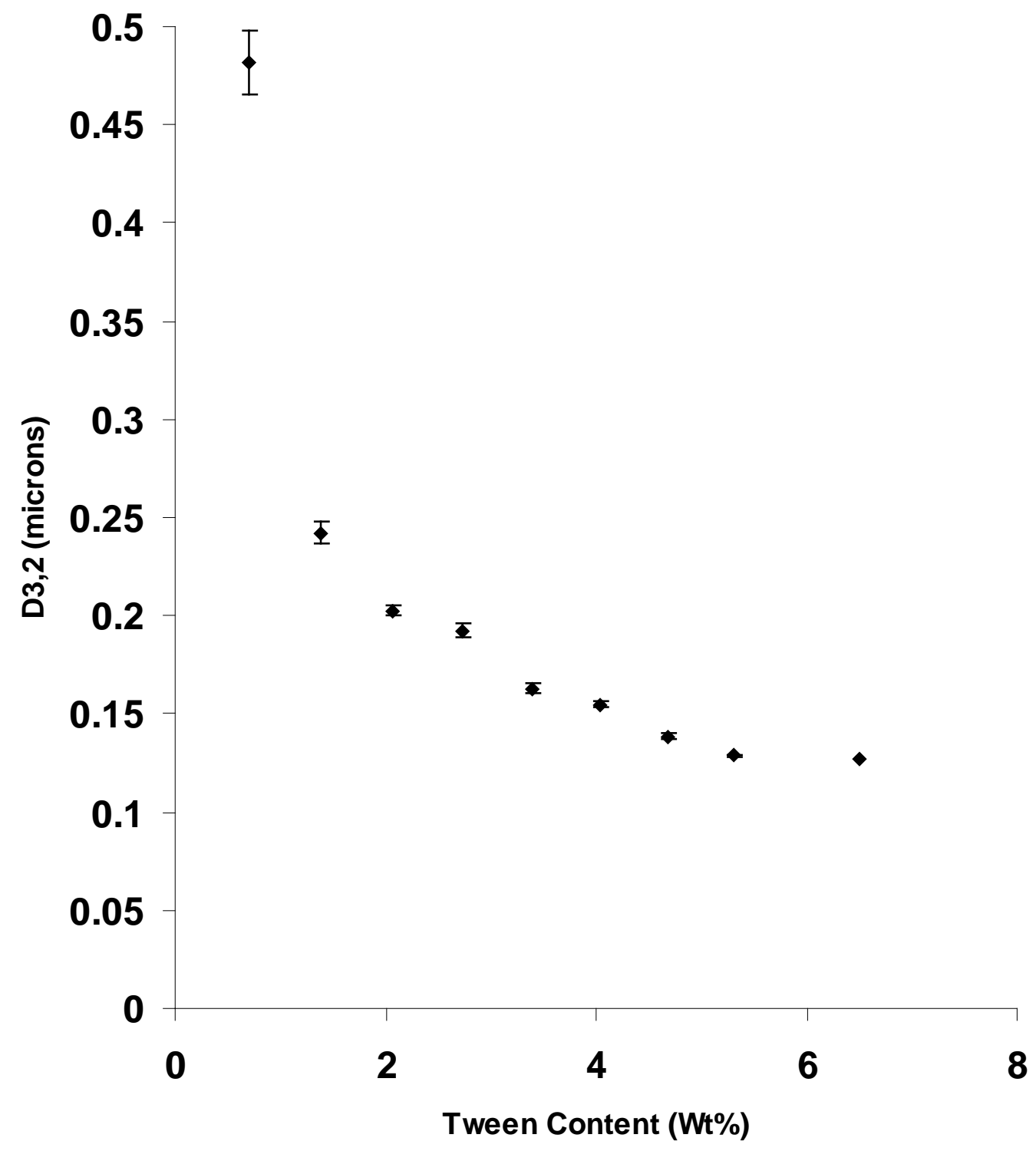

360 
$361 \quad$ Figure 3

362

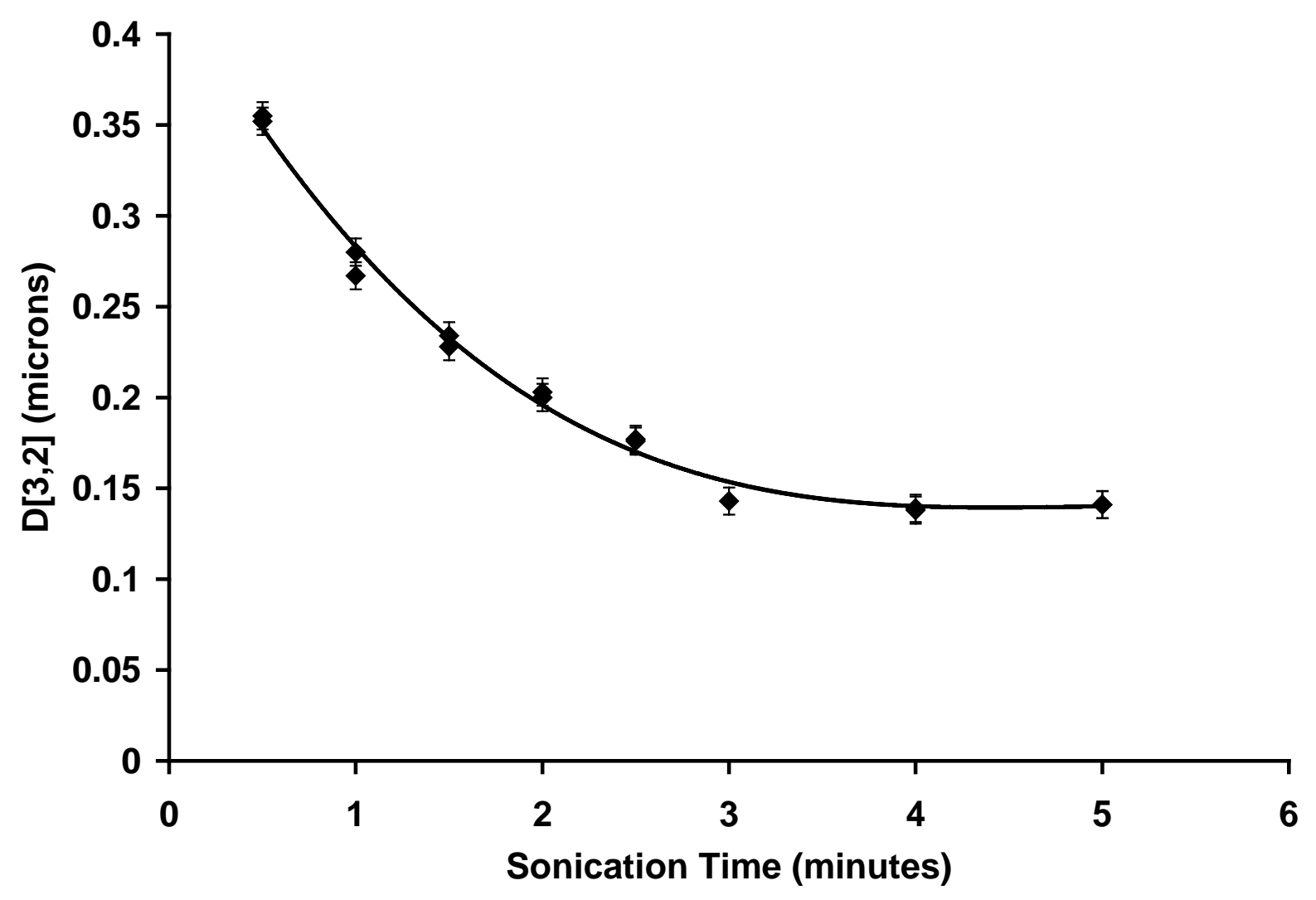

363

364

365 
Figure 4

367

368

369

370

371

372

373

374
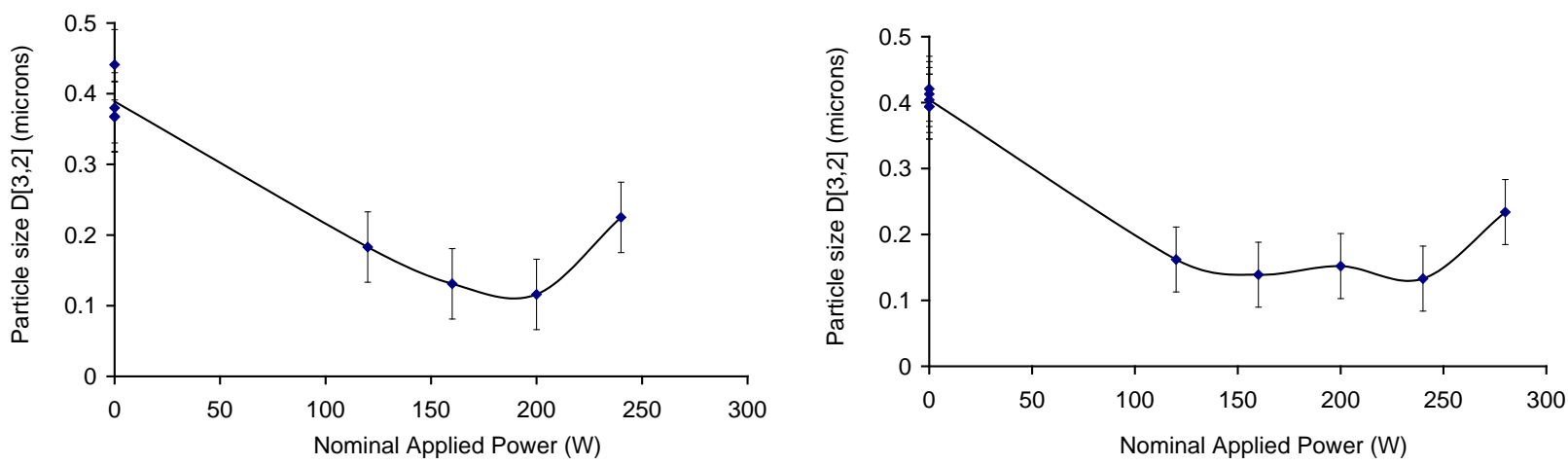

375

376 
$377 \quad$ Figure 5

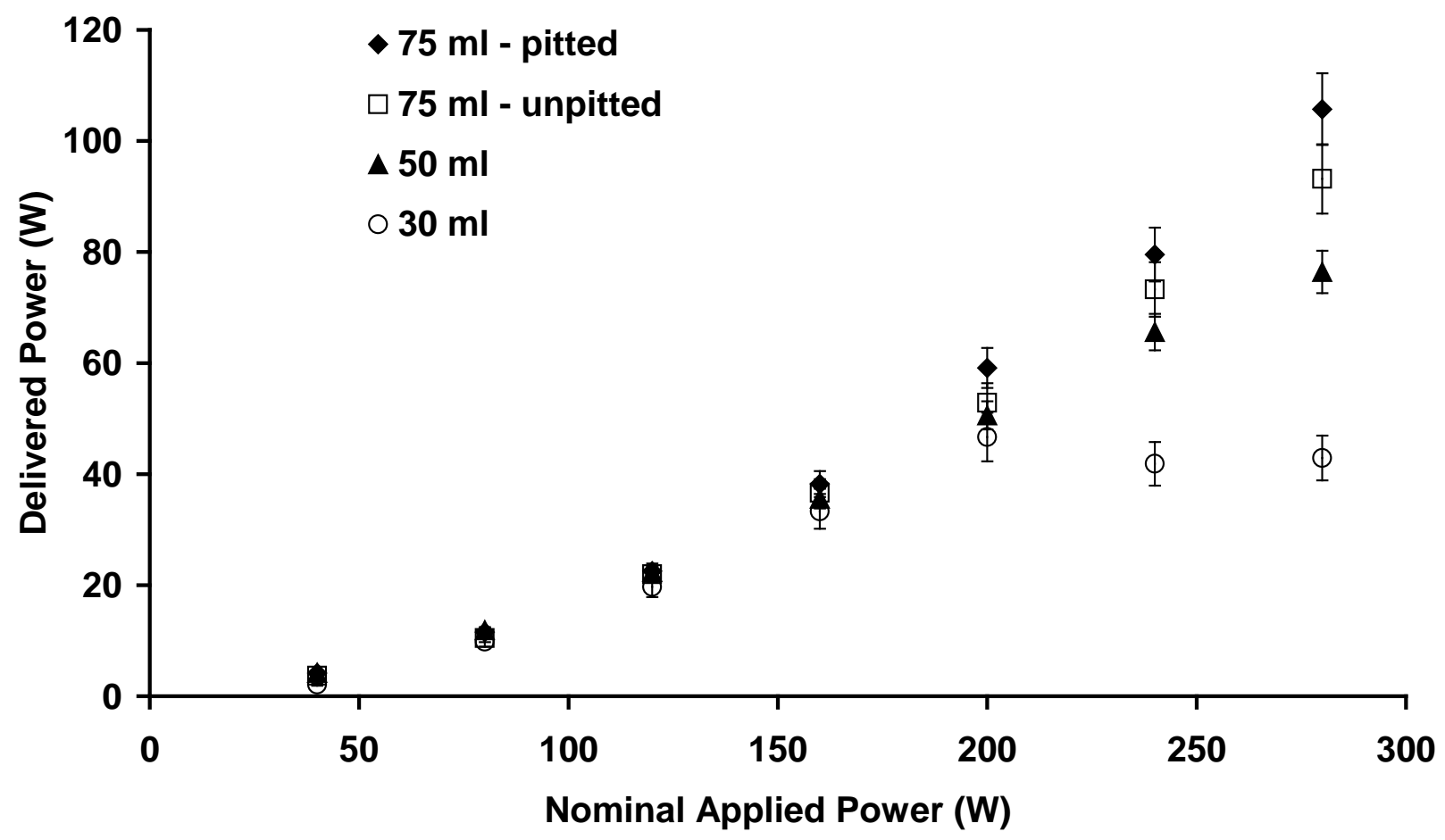

378

379

380

381

382

383

384

385

386 
387 Figure 6

388

389

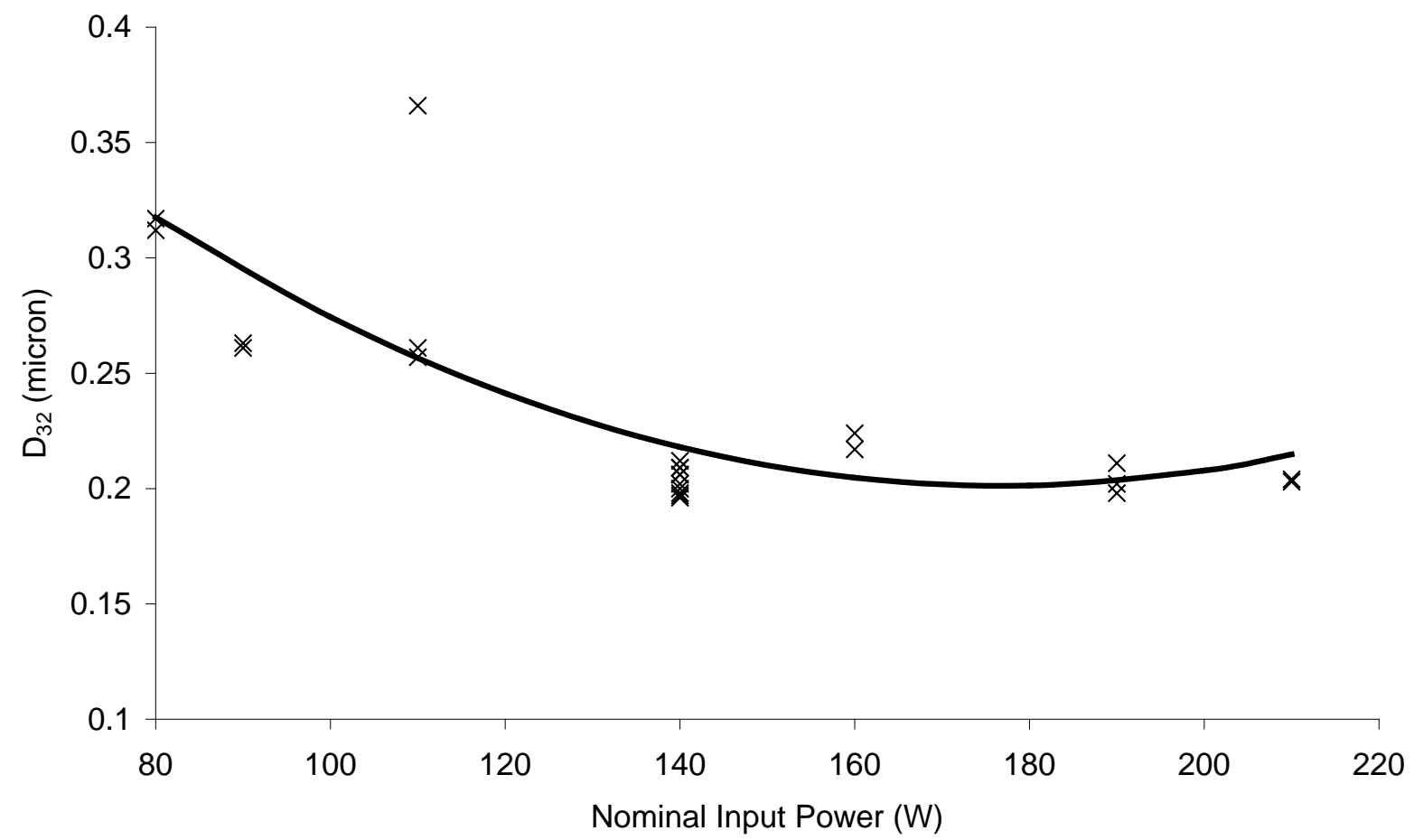


391

392

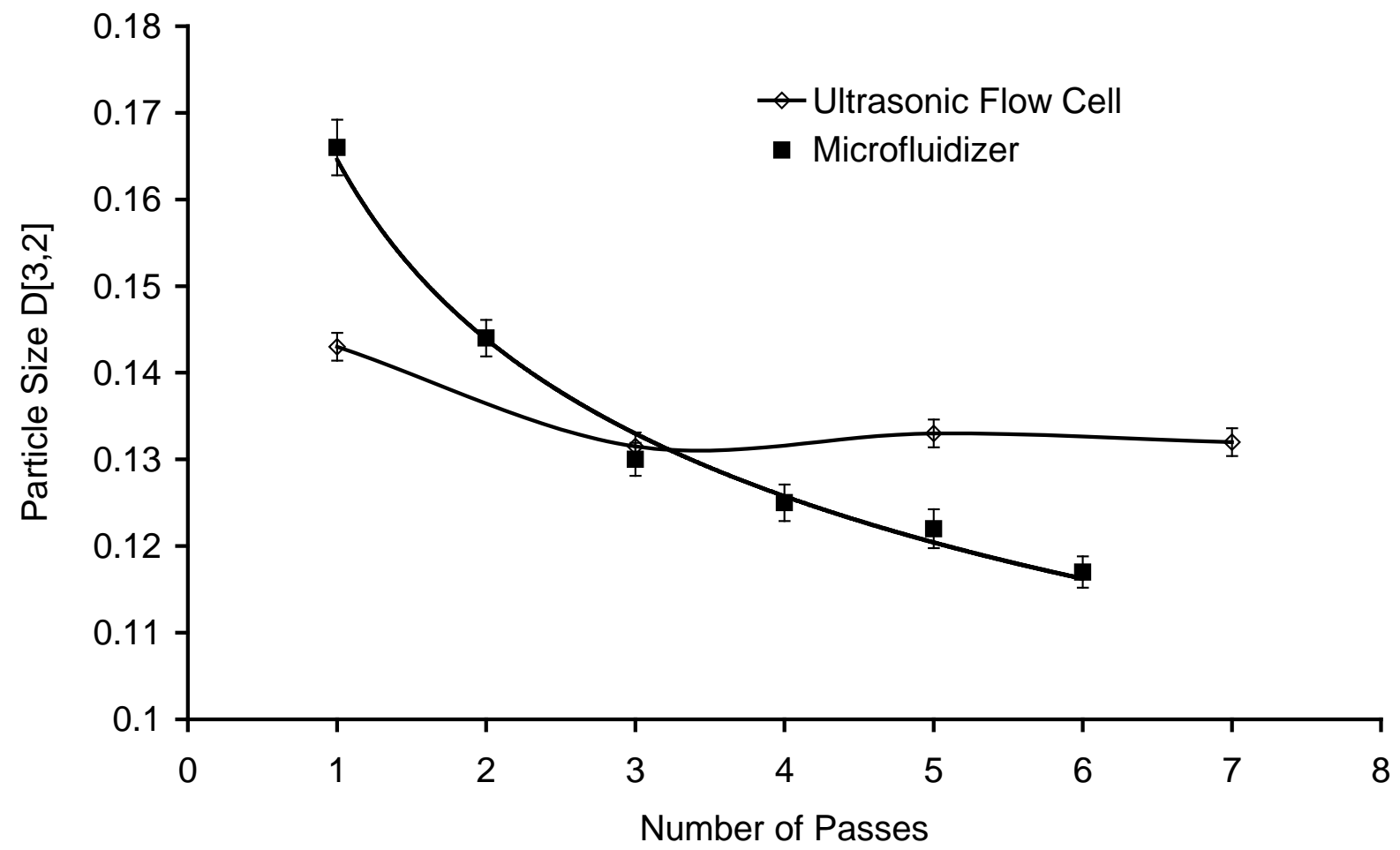

393

394 
Figure 8

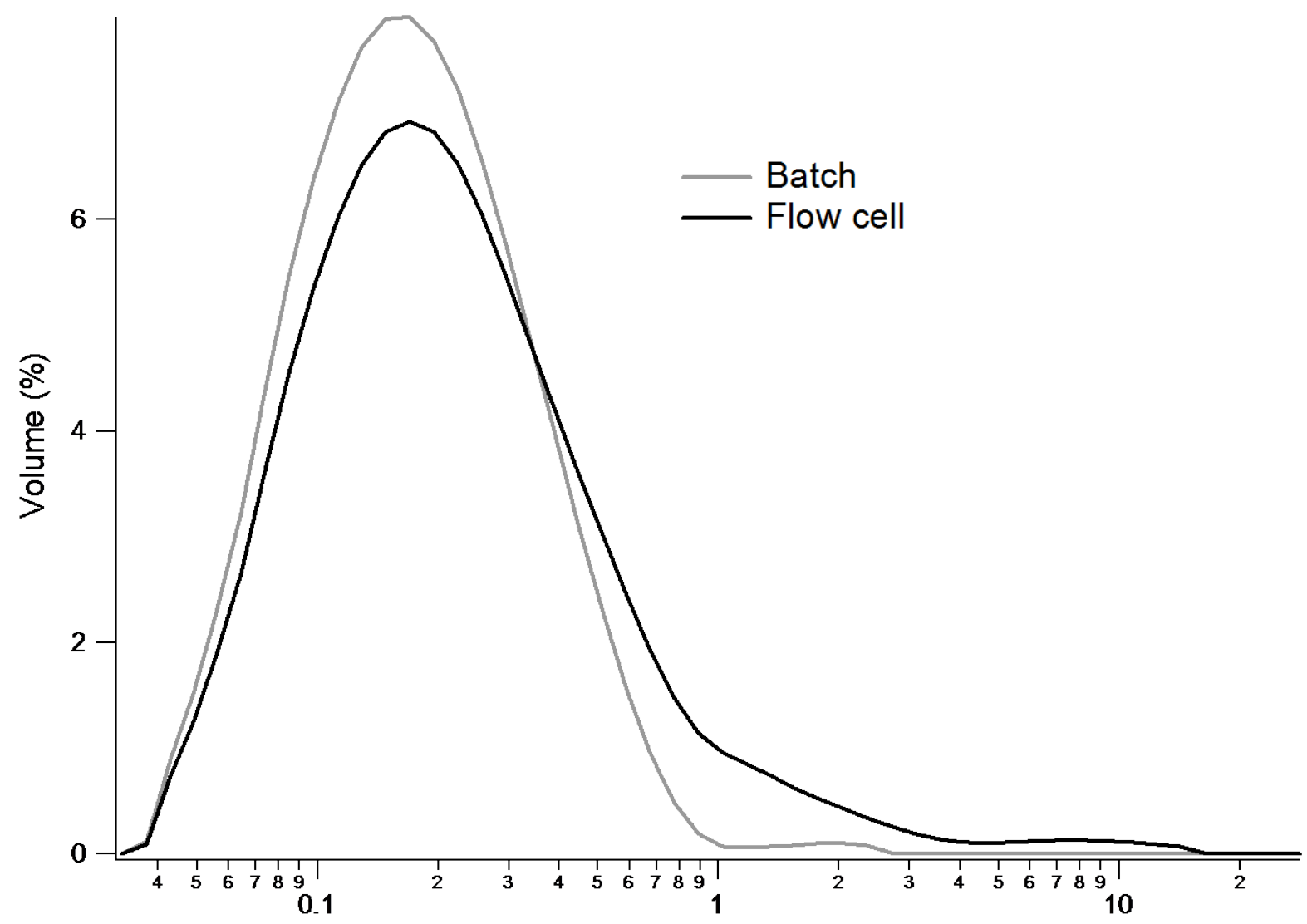

396

Particle size $(\mu \mathrm{m})$

397

398 